\title{
Multi-Sectoral Reflections and Efforts in Strengthening Partnerships to Reduce Disaster Risk in Mexico: The First MuSe- IDRiM Conference
}

\author{
Irasema Alcántara-Ayala ${ }^{1}$ Daniel Rodríguez-Velázquez ${ }^{2} \cdot$ Ricardo J. Garnica-Peña $^{1}$ \\ Alejandra Maldonado-Martínez ${ }^{3}$
}

Accepted: 12 September 2020/Published online: 28 September 2020

(C) The Author(s) 2020

\begin{abstract}
Notwithstanding the high societal impact of disasters in Mexico, there is a lack of integrated efforts to establish a sound policy for reducing disaster risk to counterbalance the existing concentrated endeavors in disaster management. In the face of such segmentation, the science and technology community has advocated for a change of perspective, from civil protection to integrated disaster risk management. The first Multi-Sectoral Conference towards Integrated Disaster Risk Management in Mexico: Building a National Public Policy (MuSe-IDRiM Conference) was held in Mexico City at National Autonomous University of Mexico, 21-24 October 2019. In support of the implementation of the Sendai Framework for Disaster Risk Reduction 2015-2030, the conference aimed at enhancing the dialogue between the science and technology community, citizens, civil society organizations, private and public sectors, and the federal, state, and municipal governments to foster the process of transforming the current National Civil Protection System into a national public policy oriented towards integrated disaster risk management (DRM). Barriers and challenges to the implementation of integrated DRM were identified. Implementation of integrated DRM challenges current socioeconomic structures and encourages all relevant stakeholders to think, decide, and act from a different
\end{abstract}

Irasema Alcántara-Ayala ialcantara@igg.unam.mx

1 Institute of Geography, National Autonomous University of Mexico (UNAM), 04510 Mexico City, Mexico

2 National School of Social Work, National Autonomous University of Mexico (UNAM), 04510 Mexico City, Mexico

3 Disaster Risk Reduction Consultant, 04700 Mexico City, Mexico perspective and within and across spatial, temporal, jurisdictional, and institutional scales. Understanding disaster risk from an integrated approach, learning skills that authorities have not learned or used, and hence, strengthening disaster risk governance are prerequisites to effectively manage disaster risk.

Keywords Disaster risk reduction - Integrated disaster risk management $\cdot$ Mexico $\cdot$ Science-based policy making $\cdot$ SINAPROC

\section{Disaster Impact in Mexico}

Disasters involve socially significant effects, directly or indirectly impacting a community and therefore constitute catalysts for change in the structure and organization of societies. Due to their disruptive nature, disasters reveal or exacerbate social situations of crisis, inequality, and unsustainable outdated skewed models of development and policy making that need to be addressed and transformed (Lavell and Maskrey 2014).

The consequences of the disasters triggered by the earthquakes of September 2017 in Mexico have reaffirmed the urgent need to link science and public policy in a context where the mostly reactive National Civil Protection System (SINAPROC) should be transformed into an integrated disaster risk management (DRM) public policy in the country. Only with the participation of different actors, including the science and technology community (STC), citizens, the private sector, and the authorities of the different levels of government, an axis of transformation can be shaped. Such transformation should seek to address disaster risk and disaster root causes and risk drivers, so that institutional efforts are not merely directed towards 
emergency response, or at promoting fragmented reconstruction actions that do not contribute to reducing vulnerability.

According to the yearly data produced by the National Centre for Disaster Prevention (CENAPRED), ${ }^{1}$ the impact of disasters in Mexico during 2000-2019 involved 3765 human losses, 56 million people affected, and approximately 1.8 million damaged dwellings and 41,109 affected schools. Economic damage was about USD 40,350 million.

\section{The First Multi-Sectoral Conference Towards Integrated Disaster Risk Management in Mexico}

Different initiatives have been organized by the STC in order to reflect on and promote disaster risk reduction (DRR) partnerships at international (Aitsi-Selmi et al. 2016; Alcántara-Ayala et al. 2017; Collins et al. 2017; Trogrlić et al. 2017) and national levels. With the participation of national experts from diverse backgrounds and various institutions, several meetings to discuss issues associated with the structure and performance of SINAPROC were held in Mexico, at National Autonomous University of Mexico (UNAM) in 2018 and 2019. Discussed issues included the identification of the challenges to be faced if a public policy on DRR from an integrated perspective is not fostered within the sphere of decision making and practice. Likewise, a review of different legal systems, programs, and guidelines related to the areas of civil protection, urban development, environment, government coordination, and public spending was undertaken to document the current state of the different public actions related to DRM, currently disarticulated and dispersed in different government agencies (Alcántara-Ayala et al. 2019)

These efforts brought up a series of recommendations addressed in June 2018 to the candidates for the Presidency of the Republic and popularly elected candidates from the three levels of government (Alcántara-Ayala et al. 2018), which in addition to the considerations derived from the debate meetings, culminated in the organization of another forum, where reflections from the academia were offered. The sum of all these learning processes and multi-, interand transdisciplinary discussions led to the proposal of the transformation of SINAPROC into an integrated system, coordination entity, or strategy for DRM (Alcántara-Ayala et al. 2019).

Owing to the absence of a National Platform for Disaster Risk Reduction (NPDRR) to interact with, and in order to support the implementation of the Sendai Framework (UNISDR 2015), the first national Multi-Sectoral

\footnotetext{
${ }^{1}$ https://www.gob.mx/cenapred.
}

Conference towards Integrated Disaster Risk Management in Mexico: Building a National Public Policy (MuSeIDRiM Conference), was organized in Mexico City at UNAM, on 21-24 October 2019.

The objectives of the MuSe-IDRiM Conference were: (1) Enhancing the dialogue between the SCT, citizens, public and private sectors, and other relevant DRR stakeholders; (2) Identifying barriers to the implementation of a national public policy oriented towards integrated DRM; and (3) Fostering and assisting the process of transforming the SINAPROC into a national system or strategy to advance integrated DRM.

The conference involved 212 participants with 101 females and 111 males from civil society, academic sector institutions, and public and private sector organizations with wide-ranging disciplinary fields, backgrounds, and experience in DRR.

Five regional-geographic related sessions focused on DRR topics pertaining to concerns at subnational level. They were intended to reflect on knowledge gaps and efforts directed towards DRR in reference to the existing research on hazard identification and assessment, analysis of vulnerability and exposure, along with the existing initiatives, strategies, and practices to promote synergies and alliances according to the different territorial contexts of the country. Based on problems whose solution poses relevant theoretical and practical challenges in the perspective of designing a national policy for DRR, thematic roundtables were planned to stimulate academic discussion in order to identify strengths and opportunities for such transformation. High-level dialogues involved the participation of public servants and experts in each area in order to reflect and examine the problems and challenges associated with the occurrence of disasters in contemporary Mexico (Table 1).

\section{Assessing Prevailing Disaster Risk Reduction Challenges}

In this section, main observations derived from the evaluation of current DRR initiatives and approaches undertaken during the MuSe-IDRiM Conference are presented.

\subsection{Regional-Geographic Related Sessions}

In the regional-geographic related sessions discussions were focused on the significance of understanding territorial contexts and differences, as well as vulnerability and risk scenarios as a methodological premise to align existing efforts to reduce disaster risk. It was argued that social, economic, cultural, environmental, ecological, and geographical heterogeneity needs to be considered in DRM, 
Table 1 Sessions of the first MuSe-IDRiM Conference

\begin{tabular}{|c|c|c|}
\hline $\begin{array}{l}\text { Regional-geographic related } \\
\text { sessions }\end{array}$ & Thematic roundtables & High-level dialogues \\
\hline North-western region & $\begin{array}{l}\text { (1) September } 2017 \text { earthquakes } \\
\text { (2) Post-disaster recovery, relocations, and } \\
\text { reconstruction }\end{array}$ & (1) Human rights, citizenship, and DRR \\
\hline North-eastern region & $\begin{array}{l}\text { (3) Civil society organizations and citizen participation } \\
\text { (4) Infrastructure and disaster risk }\end{array}$ & (2) Academy and public policy \\
\hline Western region & $\begin{array}{l}\text { (5) Education: Integrated DRM related professional } \\
\text { career service and curriculum structure } \\
\text { (6) Health and disasters }\end{array}$ & (3) Integrated territorial management \\
\hline South-eastern region & $\begin{array}{l}\text { (7) Territorial planning, environmental impact, and } \\
\text { social construction of disaster risk } \\
\text { (8) Risk atlas and information systematization }\end{array}$ & (4) Financial instruments for Integrated DRM \\
\hline Central region & $\begin{array}{l}\text { (9) Warning systems, early warning systems (EWSs), } \\
\text { and DRM } \\
\text { (10) Disasters and climate change }\end{array}$ & $\begin{array}{l}\text { (5) Challenges for the implementation of the } \\
\text { National System for Integrated DRM in the } \\
\text { context of institutional vulnerability }\end{array}$ \\
\hline
\end{tabular}

but resources were scarce and synergy among the DRR community within regions poor. Hence, it was suggested that DRR-oriented knowledge at local and community levels should be enhanced to develop eco-territorial strategies aimed to reduce disaster risk drivers, particularly poverty, marginalization, and land degradation.

\subsection{Thematic Roundtables}

Beyond the adverse effects of the disasters triggered by the earthquakes of September 2017, debates were centered on how consequences exposed the magnitude of a multidimensional problem related to the different historical dimensions of vulnerability, the multiplication of disaster risk drivers, and immediate or critical causes of disasters, especially those related to earthquake resistant building standards and construction codes, which are more often than not, ignored by real estate business. These issues are strongly linked to legal and regulatory frameworks that although can be in place, implementation of laws and sanctioning of noncompliance lack across levels of government. The rift between ordinance and practice emanates from weak governance in connection with the disjointed architecture and functionality of judicial and legislative powers and public administration across scales.

Central to this discussion was the topic of post-disaster recovery, relocation, and reconstruction after the earthquakes of 2017. Technical-engineering and social perspectives including political-legal dimensions were considered. SINAPROC lacks conceptual and practical coherence focused on integrated DRM. In terms of social participation, it has no foundations or experiences that contribute to a different design than that of aid and rescue.

Social participation would be stronger should strategies from the government include unrestricted dissemination of information, risk atlases, technical damage assessments, incorporation of human rights frameworks within the DRR sphere, creation of science based disaster risk communication, and community inclusion for disaster risk initiatives directed to housing reconstruction. Evidence showed that civil society is a team of diverse actors whose potential for knowledge and intervention has not been sufficiently valued by authorities.

A major distress about planned and ongoing megaprojects infrastructure was also revealed. This is perceived as lifesaver to confront extreme events by authorities, while other stakeholders, particularly civil society, are concerned about their role in exacerbate existing disaster risk drivers. A view on sustainable development should be therefore incorporated into infrastructure strategies, on which integrated DRM should not be disregarded.

In addition to the unambiguous relationship between science and policy making and practice, a key component for successful integrated DRM is education. However, there are certain drawbacks associated with the structure of education related to DRR nationwide. First, the complexity of designing and implementing a sound transdisciplinary curriculum on DRR across educative levels has been overlooked by different stakeholders, but particularly by the government. Second, there is a deficiency in the 
number of well-trained professionals in DRR who can be involved in the creation of educational programs. Finally, and most importantly, authorities in charge of civil protection at different government levels lack the knowledge and skills needed for proper management of disaster risk.

Further discussions illustrated a series of public health care problems after the occurrence of disasters at the municipal level linked to deficiencies of the institutional organization and infrastructure. Hence, enhancing accessibility and improving quality of health services to reduce vulnerability and during post-disaster recovery was echoed as a critical requirement for DRR.

Because territories themselves are social constructions, it is necessary to recognize interlinkages between society and territory. This would stimulate a co-design of programs, projects, and interventions considering society. Although it is well recognized that planning should be integrated in DRR, lack of or inadequate coordination between relevant institutions and ministries who are involved in environment, planning, health, education, development, and other disaster risk related issues, was identified.

Hazard monitoring is privileged over integrated research as a result of traditional monodisciplinary practices or due to the possibility of obtaining resources to reinforce existing information systems and models with no integrative approach to reduce disaster risk. Therefore, new strategies should foresee how addressing local vulnerability and exposure issues can contribute to deeper understanding of the complexity of disaster risk and reducing the impact of disasters on the community and region.

High-level monitoring strategies for some hazards have been developed. Nonetheless, arguments also reflected the urgency to standardize and exchange information on existing hazard monitoring systems, and especially to address current limitations due to lack of resources in state public universities to maintain monitoring equipment and absence of interinstitutional support approaches.

Concerns were highlighted in reference to forecasting and EWSs. Beyond technical approaches focused on preparedness and mitigation procedures, EWSs should be enhanced to achieve efficiency and reliability as instruments for integrated DRM, rather than as conjunctural communication systems, detached from social processes. Early warning system design should not be limited to infrastructure, equipment, and information technology devices for alerting and delineating evacuation actions. They must include people and communities' perspectives on DRR.

Issues related to potential impacts of climate change on disasters were particularly prominent in terms of assessing regional and national knowledge and uncertainty. Evaluation of institutional capacity at subnational and local levels, along with the needs and costs of adaptation were recurred themes. It was also noted that articulated mitigation and adaptation decisions and actions could contribute to strengthening integrated DRM.

\subsection{High-Level Dialogues}

Owing to an absence of dissemination and disclosure of information that prevent people from making informed decisions, lack of democratization of knowledge violates human rights. In a disaster situation people face violations of various rights. Under disaster risk and disaster contexts, the human sphere of integrated DRM should comprise economic, social, cultural, and environmental rights as well as civil and political rights, so that citizenship can be built.

Science and technology community should be intrinsically linked to policy making and practice. Contrary to expectations, there is not an encouraging balance yet since this type of synergies are circumstantial and technical approaches prevail. Poor government interest and commitment to address social, economic, cultural, environmental, territorial, and political matters based on science information and knowledge has been observed.

Due to the constant expansion of weak legal and planning strategies during several decades, a series of problems producing disaster risk drivers persist in the territory, especially in the cities. Lack of understanding of the territory from an integrated perspective by the institutions hinders consistent public policies.

There are two main financial instruments: FONDEN and FOPREDEN. FONDEN, Mexico's Fund for Natural Disasters, relies on federal budget funds, and financial risk transfer instruments. It aims to take actions and apply resources to mitigate the effects of disasters regarding emergency response and reconstruction. FOPREDEN, the Mexican Federal Fund for the Prevention of Natural Disasters, is a federal fund established to support disaster prevention activities by cofinancing local disaster prevention projects.

These financial instruments have been designed from a civil protection perspective as they have been mainly focused on the application of post-disaster measures and development of infrastructure projects. The imbalance of these funds is expressed through their contrasting investment. While for instance during 2013-2017, 114,497 million pesos (USD 6735 million) were financed via FONDEN (Presidencia de la República 2017, 2018), only 2482 million pesos (USD 146 million) were provided by FOPREDEN (Rodríguez 2017); the ratio of disaster response and recovery to prevention expenditures was $46: 1$. 


\section{Overarching Reflections, Challenges, and Future Directions}

In the absence of a NPDRR, and therefore, of a nationally led forum or mechanism for support, coordination, analysis, and advice on DRR that considers the participation of the varies relevant stakeholders (UNISDR 2017), the STC has advocated for a change from civil protection to integrated DRM beyond the sphere of direct control.

One of the great challenges of integrated DRM is to have all stakeholders understand the way environment and society are intertwined, and disaster risk and disasters as socially constructed processes.

Given the importance of understanding disaster risk for DRM, it is essential that authorities in charge have a deep understanding of disaster risk. However, there is lack of or inadequately trained professionals in charge of civil protection institutions at different levels of government who are knowledgeable about disaster risk and DRM. Consequently, addressing DRR will require all relevant stakeholders to think, decide, and act from a different perspective. It also will involve understanding disaster risk from an integrated approach and learn skills that authorities have not learned or used.

Prevalence of traditional monodisciplinary efforts focused on hazard understanding makes the incorporation of sustainability frameworks to reduce disaster risk, which is transdisciplinary, a strenuous endeavor. Without a national disaster risk policy, local action for disaster risk reduction and sustainable development can be limited. Accordingly, concerted efforts and resources to institutionalize DRR from an integrated perspective into sciencebased programs, practices, and policies should not be neglected.

Observed intragovernmental disagreements are reflected on lags and lack of federal financial and institutional support for DRR at the federal, state, and municipal scales. Such failure is linked to both lack of understanding of disaster risk and inadequate institutional structures that support transformative efforts to reorient disaster management to address disaster root causes and risk drivers.

To improve the STC-policy making interface, the most urgent strategies are:

(1) Enhancing professional development in DRR that draw together essential skills, cross-curricular approaches, and action-based learning capabilities for public servants and all relevant DRR stakeholders;

(2) Strengthening collaboration among universities and building partnerships between the STC and authorities to ensure science-based or informed decision making becomes the norm rather than random events;

(3) Increasing integrated disaster risk research;

(4) Creating scientific committees to support policy making at subnational, state, and if possible, municipal levels;

(5) Working systematically at the regional, provincial, and community scales;

(6) Conducting research to establish and strengthen a solid community of practice;

(7) Setting up North-South and South-South cooperation mechanisms around DRR to share experiences;

(8) Developing strong subnational consortium of stakeholders to support DRR and DRM initiatives;

(9) Working with mass media to disseminate DRR and integrated DRM; and

(10) Strengthening local, national, regional, and international networks to help overcome difficulties and barriers at institutional and governmental levels.

Last but not least, delineation and implementation of DRR policies should consider human rights from a perspective on which, the "Formula of Humanity" created by Kant is taken as a baseline: "So act that you treat humanity, whether in your own person or in the person of any other, always at the same time as an end, never merely as a means" (Atwell 1986).

In summary, the main hindrance to reorienting disaster management to address disaster risk in Mexico is related to lack of or inadequate understanding of disaster risk, deficient knowledge and skills needed for proper management of disaster risk, failure to implement legal frameworks, weak disaster risk governance, and practice of priorities in the benefit of economic interests impinging upon science informed decision making.

Disaster risk reduction cannot continue to be an optional realm. Seeking transformative efforts of the current civil protection perspective directed towards integrated DRM should not be any longer reflected only in a written form in the legal existing frameworks but in policy making and practice at the federal, state, and local levels.

Acknowledgements Thanks are due to all participants, and to the Institute of Geography, National School of Social Work and Coordination of Scientific Research of the National Autonomous University of Mexico (UNAM) and Citibanamex for providing financial support for the organization of the MuSe-IDRiM Conference. We are also grateful to the Editors of the journal whose suggestions helped to improve this manuscript.

Open Access This article is licensed under a Creative Commons Attribution 4.0 International License, which permits use, sharing, adaptation, distribution and reproduction in any medium or format, as long as you give appropriate credit to the original author(s) and the source, provide a link to the Creative Commons licence, and indicate if changes were made. The images or other third party material in this 
article are included in the article's Creative Commons licence, unless indicated otherwise in a credit line to the material. If material is not included in the article's Creative Commons licence and your intended use is not permitted by statutory regulation or exceeds the permitted use, you will need to obtain permission directly from the copyright holder. To view a copy of this licence, visit http://creativecommons. org/licenses/by/4.0/.

\section{References}

Aitsi-Selmi, A., V. Murray, C. Wannous, C. Dickinson, D. Johnston, A. Kawasaki, A.-S. Stevance, and T. Yeung. 2016. Reflections on a science and technology agenda for 21 st century disaster risk reduction. International Journal of Disaster Risk Science 7(1): $1-29$.

Alcántara-Ayala, I., K. Sassa, M. Mikoš, Q. Han, J. Rhyner, K. Takara, S. Nishikawa, B. Rouhban, et al. 2017. The 4th World Landslide Forum: Landslide research and risk reduction for advancing the culture of living with natural hazards. International Journal of Disaster Risk Science 8(4): 498-502.

Alcántara-Ayala, I., M. Garza-Salinas, L. Lucatello, J.M. MacíasMedrano, E. Mansilla, V. Magaña Rueda, S. Puente-Aguilar, D. Rodríguez-Velázquez, et al. 2018. The future of integrated disaster risk management in Mexico: A public policy seen by the science community (2018-2024) (El futuro de la Gestión Integral del Riesgo de Desastres en México: una visión de Políica Pública desde la Academia (2018-2024)). Unpublished paper (in Spanish).

Alcántara-Ayala, I., M. Garza Salinas, A. López García, V. Magaña Rueda, O. Oropeza Orozco, S. Puente Aguilar, D. Rodríguez Velázquez, S. Lucatello, et al. 2019. Integrated disaster risk management in Mexico: Reflections, challenges, and proposals from the academic community seeking a transformation on policy making (Gestión Integral de Riesgo de Desastres en México: reflexiones, retos y propuestas de transformación de la política pública desde la academia). Investigaciones Geográficas 98: 1-17 (in Spanish).
Atwell, J.E. 1986. Ends and principles in Kant's moral thought. Dordrecht: Springer.

Collins, A., H. Tatano, W. James, C. Wannous, K. Takara, V. Murray, C. Scawthorn, J. Mori, et al. 2017. The 3rd Global Summit of Research Institutes for Disaster Risk Reduction: Expanding the platform for bridging science and policy making. International Journal of Disaster Risk Science 8(2): 224-230.

Lavell, A., and A. Maskrey. 2014. The future of disaster risk management. Environmental Hazards 13(4): 267-280.

Presidencia de la República. 2017. National government report 2016-2017 (5to. Informe de gobierno 2016-2017), Anexo Estadístico, México (in Spanish).

Presidencia de la República. 2018. National government report 2017-2018 (6to. Informe de gobierno 2017-2018), Anexo Estadístico, México (in Spanish).

Rodríguez, D. 2017. Limitations and challenge of the legal, programmatic framework and financial instruments for the management of civil protection and climate change (Limitaciones y desafío del Marco Jurídico, Programático e Instrumentos Financieros para la Gestión de la Protección Civil y el Cambio Climático). In Climate change and disasters: A public policy approach (Cambio Climático y Desastres: un enfoque en Politicas Públicas). Universidad Nacional Autónoma de México (UNAM) y Programa de Investigación en Cambio Climático (PINCC), ed. S. Lucatello, and M. Garza, 55-70 (in Spanish).

Trogrlić, R.S., L. Cumiskey, A. Triyanti, M.J. Duncan, N. Eltinay, R.J. Hogeboom, M. Jasuja, C. Meechaiya, et al. 2017. Science and technology networks: A helping hand to boost implementation of the Sendai Framework for Disaster Risk Reduction 2015-2030? International Journal of Disaster Risk Science 8(1): $100-105$.

UNISDR (United Nations International Strategy for Disaster Reduction). 2015. Sendai framework for disaster risk reduction 20152030. Geneva: UNISDR.

UNISDR (United Nations International Strategy for Disaster Reduction). 2017. Report of the open-ended intergovernmental expert working group on indicators and terminology relating to disaster risk reduction. Geneva: UNISDR. 